\title{
Awareness, treatment and control of hypertension among the elderly living in their home in Tunisia
}

Sonia Hammami ${ }^{1,2^{*}}$, Sounira Mehri ${ }^{1}$, Said Hajem ${ }^{3}$, Nadia Koubaa ${ }^{1}$, Mohamed A Frih ${ }^{1,4}$, Samy Kammoun ${ }^{5}$, Mohamed Hammami ${ }^{1}$ and Fathi Betbout ${ }^{1,6}$

\begin{abstract}
Background: Hypertension is a cardiovascular disorder rapidly emerging as a major public health problem in developing countries. However, the acknowledgement of the prevalence and the significant impact of hypertension in elderly are very important for health policy. The objective of the present investigation was to evaluate the prevalence, awareness and treatment of hypertension among the elderly living in their home in Tunisia at Monastir City. We also examined the impact of socio-demographic characteristics and known risk factors for high blood pressure.
\end{abstract}

Methods: A community based sample of 598 non-institutionalized elderly (age $\geq 65$ years), was selected using probabilistic multistage cluster sampling.

Results: There was a predominance of female (66\%) and mean age was $72.3 \pm 7.4$ years. The prevalence of hypertension was $52 \%(n=311)$, awareness $(81 \%, n=252)$, treatment $(78.4 \%, n=244)$ and only $30.7 \%(n=75)$ are correctly treated. The prevalence of hypertension was higher for the female population (55.5\%) when compared to males (45\%). No urban/rural differences were observed and no difference was observed by educational level. Multiple logistic regression analyses identified a higher body mass index, diabetes mellitus and disability as important correlates of the prevalence of hypertension.

Conclusion: These findings provide important information on the prevalence, awareness and control of hypertension in Monastir City and confirm their association with other cardio-vascular risk factors. Effective public health measures and strategies are needed to improve prevention, diagnosis and access to treatment of this elderly population.

Keywords: Hypertension, Elderly, Prevalence, Awareness, Tunisia, Home living

\section{Background}

Hypertension is the leading cause of cardiovascular disease worldwide. Recent studies demonstrate that there is a linear correlation between blood pressure and cardiovascular events [1]. Hypertension is also a major cause of disability, causing an estimated $13 \%$ of all deaths in the world [2]. More than $20 \%$ of adults are hypertensive with a very poor rate of control and only one third of hypertensive patients treated achieve the correct goal of

\footnotetext{
* Correspondence: Sonia.Hammami@fmm.rnu.tn

${ }^{1}$ Laboratory of Nutrition and Vascular Health, Faculty of Medicine, University of Monastir, Tunisia

Full list of author information is available at the end of the article
}

blood pressure [3]. Age represents a determining factor in the prevalence of arterial hypertension. Epidemiological research has demonstrated that age plays an important role in increasing pressure value, especially systolic blood pressure that tends to increase with age $[4,5]$. Acknowledgement of the prevalence and the significant impact of hypertension in elderly, on the cardiovascular risk and quality of life are very important for health policy and public health strategy in developing countries.

In Tunisia, the population aged 65 years has exceeded $7 \%$ since 2009 [6]. The prevalence of hypertension has not been well studied. The present epidemiological study was performed to estimate the prevalence, 
awareness and treatment of hypertension in the elderly people living in their home (community dwelling elderly) in Monastir city and to discuss the potential risk factors for hypertension and its association with other cardiovascular risk factors.

\section{Methods}

Data for this study are from a population based survey undertaken in 2008-2009 to investigate social, health behaviours and health status of people aged 65 years and over living in their home in Monastir (center-ouest in Tunisia). Monastir is a governorate of about 494900 inhabitants. The city was divided into 77 sectors and 13 delegations based on the list of the last population census in 2004 (National Institute of Statistics, unpublished data). Ethical approval was granted by the Clinical Research Ethics Committee of the University Hospital of Monastir and Ministry of health. This study was supported by grants from World Health Organisation and the United Nations Population Fund.

\section{Study Population}

We conducted cross-sectional community-based study carried out thought home questionnaires, with a random sampling process of Monastir's non institutionalized elderly individuals (aged more than 65 years). We used a probabilistic multistage cluster sampling technique in two phases. The first consisted in the identification of the districts; eighteen sectors were selected, than we selected randomly a cluster of household with a probability of selection proportional to the size of their population. We identified elderly subjects within the household clusters. At the selected homes one or two resident was interviewed. The participants were previously informed about this study by social assistant of the region to maximize response rates. Three doctors performed a door-to-door survey of the participant households. Any elderly subject refusing to take part in the study will be granted the freedom to do so. The investigator also respects the decision of the old person's attendants and relatives if they express the wish not to allow the elderly person to take part in this study. In all cases, informed consent was obtained from subjects or cohabiting. No response subjects $(n=22)$ were replaced by others eligible subjects, a next neighbor was chosen in the same way. The parameters used to calculate the sample size were the proportion of elderly, maximum allowed $95 \%$ confidence interval with a margin of error no more than $3 \%$. An extra of $50 \%$ were added to the sample obtained $(n=400)$ to cover losses, resulting in $n$ $=600$. A total of 598 individuals were investigated. The exclusion criteria were individuals aged less than 65 years. Any elderly present, the day of the visit by investigators, in the surveyed household found to be a visitor or do not usually leave there will be excluded.

\section{Subject Evaluation}

Information was gathered by home-based personal interview using a structured questionnaire with 90 parameters conducted in three parts: standard questions on demographic, socioeconomic information and health behaviors, followed by a physical examination: anthropometric and blood pressure measurements. The questionnaire was translated from French into Arab by the principal investigator and another Tunisian physician and compared before being distributed. Before participation respondents were informed that participation was voluntary, and that they could quit out at any time.

Blood pressure (BP) was measured twice using standard sphygmomanometer, with participants seated after 5 minutes. For analysis we used the mean of the 2 measurements. High BP was defined as systolic blood pressure $(\mathrm{SBP}) \geq 140 \mathrm{mmHg}$ and/or diastolic pressure (DBP) $\geq 90 \mathrm{~mm} \mathrm{Hg}$ [7]. Arterial hypertension (AH) was defined as having high BP or using antihypertensive drug therapy in the previous 2 weeks. Awareness of hypertension reflected a previous diagnosis of hypertension. Controlled hypertension was defined as treated hypertension with $\mathrm{SBP}<140 \mathrm{mmHg}$ and DBP $<90 \mathrm{mmHg}$. Anthropometric measurements were obtained with the participants wearing light clothing and no footwear. Height was measured without shoes, to the nearest $0.1 \mathrm{~cm}$, with subjects standing fully erect on a flat surface, tocks and shoulders flat to the wall and looking straight ahead. Weight was to the nearest $0.1 \mathrm{~kg}$ using digital scale. Body Mass Index (BMI) was calculated as weight (in kilograms) divided by squared height (in meters squared) and further. The BMI classified individuals, using World Health Organization criteria, as normal $\left(<25 \mathrm{~kg} / \mathrm{m}^{2}\right)$, Overweight $(25-29.9 \mathrm{~kg} /$ $\left.\mathrm{m}^{2}\right)$ and obese $\left(\geq 30 \mathrm{~kg} / \mathrm{m}^{2}\right)$ [8]. Waist circumference was measured to the nearest centimeter at the level of the midpoint between the inferior border of the ribs and the iliac crest in the midaxillary line, at the end of expiration, using a constant tension tape, directly over light clothing. The waist circumference (WC) normal range was that recommended by the National Cholesterol Education Program ATP III. The WC $<88 \mathrm{~cm}$ for women and $<$ $102 \mathrm{~cm}$ for men was classified as normal [9]. The diagnosis of diabetes mellitus was established by history or use of glucose-lowering drugs in the previous 2 weeks [10]. Marital status was categorized as married or single, divorced, widows, widowers and never married persons were included in the single group. Smoking status (current smokers or not), and physical activity (walking for at least $1 \mathrm{~h}$ per day or not). Education was recorded on four levels scale: (illiterate, kuttabs 'koranic schools', primary, 
secondary or more). The diagnosis of disability was made by assessing limitations on basic activities of daily living according to Katz's test, was defined as the inability to do one or more of the following without help: bathe, eat, dress, transfer from a bed to a chair, use the toilet, or walk across a small room. Depression symptoms were assessed using a mini-Geriatric Depression Scale miniGDS, a mini-GDS Scale $\geq 1$ was considered indicative of depression [11].

We built in several quality and control measures into our survey protocol, to ensure completeness and comparability of blood pressure and anthropometric measurements and interviewee responses. For this all three doctors, underwent a common training program at the National Institute of Public Health at which a team of cardiologists instructed the investigators regarding measured of BP, weight and height. The questionnaire items were tested for clarity and validity.

\section{Statistical analysis}

The data were collected in a database and transferred to our coordinating center for statistical analysis. Every month a meeting was organised for all participating investigators to discuss the progress of the study. A total of 598 subjects were analysed using SPSS13 statistical software packages. Results are expressed as mean with the corresponding standard deviations. For statistical significance of the difference between two mean values, a Student $t$ test was used. Comparison of frequencies was performed by chi2 tests with the Yates correction when needed. Multivariate analysis between statistically significant variables and hypertension (dichotomous dependent variable) was performed using a logistic regression model. The independent variables were modelled categorically, using dummy terms.

\section{Results}

\section{Description of study subjects}

Table 1 gives a breakdown of the sample characteristics, there is more female than male (66\% VS. 34\%) and mean age was $72.3 \pm 7.4$ years. Most subjects were aged $<70$ years (38\%) but only $18 \%$ were over 80 years of age. The population under study was predominantly urban (more than three quarters). Only about $14 \%$ are from rural sites. Approximately three quarters of the subjects had no formal education and only $5 \%$ had secondary or higher education. Most of our population are still married (60\%) and $61 \%$ are inactive. Only 35\% are current smokers. Smoking prevalence is notably high for male $(98 \%)$ compared to female $(2.3 \%)$. Health insurance covered more than half of our population (57\%).

\section{Hypertension prevalence}

The prevalence of hypertension was $52 \%(\mathrm{n}=311)$ and was predominant in women (women $55.5 \%$, men $45 \%$, p
Table 1 Characteristics of elderly population in Monastir City

\begin{tabular}{|c|c|c|c|}
\hline Patient characteristic & $\begin{array}{c}\text { Characteristics of elderly } \\
\text { population }\end{array}$ & $N$ & $\%$ \\
\hline \multirow[t]{2}{*}{ Sex } & - Men & 202 & 34 \\
\hline & - Women & 396 & 66 \\
\hline \multirow[t]{4}{*}{ Age (years) } & $<70$ & 227 & 38 \\
\hline & $70-74$ & 142 & 24 \\
\hline & $75-79$ & 122 & 20 \\
\hline & $\geq 80$ & 107 & 18 \\
\hline \multirow[t]{2}{*}{ Place of residence } & - Urban & 516 & 86 \\
\hline & - Rural & 82 & 14 \\
\hline \multirow[t]{2}{*}{ Marital Status } & - Married(e) & 359 & 60 \\
\hline & - Single & 239 & 40 \\
\hline \multirow[t]{2}{*}{ Smoking Status } & -Current smokers & 208 & 35 \\
\hline & -Non smokers & 390 & 65 \\
\hline \multirow[t]{5}{*}{ Educationnel levels } & - Illiterate & 460 & 77 \\
\hline & - (kuttabs: koranic schools) & 72 & 12 \\
\hline & - Primary & 34 & 6 \\
\hline & - Secondary or higher & 32 & 5 \\
\hline & - Farmer & 82 & 14 \\
\hline \multirow{4}{*}{$\begin{array}{l}\text { Socio-professional } \\
\text { activities }\end{array}$} & - Artisans, business & 16 & 3 \\
\hline & - Liberal profession & 8 & 1 \\
\hline & - Workers & 127 & 21 \\
\hline & - Inactifs & 365 & 61 \\
\hline
\end{tabular}

$<0.01)$. The prevalence of hypertension increased with age until 80 years then decrease. At age less than 70 years, there are $51.5 \%$ compared with $55 \%$ of those aged 75 to 79 years and only $45.8 \%$ of those aged more than 80 years (Table 2). The mean systolic blood pressure values were $135.2 \pm 17.0 \mathrm{mmHg}(85-21.5 \mathrm{mmHg})$, while mean diastolic blood pressure values were $80.0 \pm$ $10.2 \mathrm{mmHg}$ (5.5 - $12.5 \mathrm{mmHg})$. Isolated systolic hypertension was the most common form of hypertension (50.9\%) of all hypertensive subjects who had elevated blood pressure at examination, followed by combined systolic and diastolic hypertension (45.7\%) and isolated diastolic hypertension (3.4\%).

The proportion of subjects aware of their elevated blood pressure status was $81 \%(\mathrm{n}=252)$, the majority $(78.4 \%, \mathrm{n}=244)$ of these were taking pharmacological treatment for hypertension. However, only about $30.7 \%$ $(\mathrm{n}=75)$ of the treated subjects had their blood pressure controlled to normal levels according to current JNCVII recommendation [7].

\section{Socio-demographic and clinical correlates of hypertension} Tables 2 examine the frequency of socio-demographic and cardiovascular risk in normotensive and hypertensive participants. Schooling showed an inverse association but not significantly $(\mathrm{p}=0.08)$ with hypertension, with a prevalence of $54 \%$ among analphabetic and $31.2 \%$ 
Table 2 Prevalence of arterial hypertension according to socio-demographic variable, anthropometric measurements and cardiovascular risk factors of elderly population in Monastir city

\begin{tabular}{|c|c|c|c|}
\hline Variable & $\mathrm{N}$ & $\begin{array}{l}\text { Prevalence of } \\
\text { Hypertension }\end{array}$ & $p$ value $^{b}$ \\
\hline \multicolumn{4}{|l|}{ Gender } \\
\hline Female & 396 & $220(55.5)^{\mathrm{a}}$ & \\
\hline Male & 202 & $91(45)$ & $P<0.05$ \\
\hline \multicolumn{4}{|l|}{ Age (years) } \\
\hline$<70$ & 227 & $117(51.5)$ & \\
\hline $70-74$ & 142 & $78(55)$ & \\
\hline 75-79 & 122 & $67(55)$ & \\
\hline$\geq 80$ & 107 & $49(45.8)$ & $P<0.01$ \\
\hline \multicolumn{4}{|l|}{ Schooling } \\
\hline Illiterate & 460 & $248(54)$ & \\
\hline Kuttab (koranic schools) & 72 & $37(51.3)$ & \\
\hline Primary & 34 & $16(47)$ & \\
\hline Secondary or more & 32 & $10(31.2)$ & $p=0.08$ \\
\hline \multicolumn{4}{|l|}{ Dependency } \\
\hline Intense & 57 & $39(68.4)$ & \\
\hline Moderate & 150 & $86(57.3)$ & \\
\hline Autonomy + & 391 & $186(47.5)$ & $P<0.01$ \\
\hline \multicolumn{4}{|l|}{ Place of residence } \\
\hline Urban & 516 & $270(52.3)$ & NS ${ }^{c}$ \\
\hline Rural & 82 & $41(50)$ & \\
\hline \multicolumn{4}{|l|}{ Depression } \\
\hline Mini-GDS < 1 & 462 & $232(50.2)$ & \\
\hline Mini-GDS $\geq 1$ & 136 & $79(58)$ & NS \\
\hline \multicolumn{4}{|l|}{ Marital status } \\
\hline Married & 359 & $187(52)$ & \\
\hline Single & 239 & $124(51.8)$ & NS \\
\hline \multicolumn{4}{|l|}{ Physical activity } \\
\hline Yes & 23 & $8(34.7)$ & \\
\hline No & 575 & $303(52.6)$ & NS \\
\hline \multicolumn{4}{|l|}{ Diabetes } \\
\hline Absent & 434 & $195(45)$ & \\
\hline Present & 164 & $116(70.7)$ & $P<0.001$ \\
\hline \multicolumn{4}{|l|}{$\begin{array}{l}\text { Overweight }\left(\mathrm{kg} / \mathrm{m}^{2}\right) \\
\quad(\mathrm{n}=531)\end{array}$} \\
\hline $\mathrm{BMl}<25$ & 106 & $31(29.2)$ & \\
\hline BMI: 25-29.9 & 165 & $81(49)$ & \\
\hline $\mathrm{BMI} \geq 30$ & 260 & $167(64.2)$ & $p=0.000$ \\
\hline \multicolumn{4}{|l|}{$\begin{array}{l}\text { Abdominal } \\
\text { circumference }\end{array}$} \\
\hline \multicolumn{4}{|l|}{$(n=531)$} \\
\hline Normal & 142 & $47(33)$ & \\
\hline Increased & 389 & $235(60.4)$ & $P=0.000$ \\
\hline
\end{tabular}

${ }^{a}$ Figures in parentheses are percentages ${ }^{b}$ chi2 test ${ }^{c}$ not statistically significant

among those with than secondary education level. No urban/rural differences were observed. Depression, marital status, and self reported physical activity were not correlated with the prevalence of hypertension. Smoking status is negatively but not significantly associated with $\mathrm{AH}$ (results not shown).

Those with hypertension had higher BMI, waist circumference, and diabetes $(\mathrm{p}<0.05)$. Regarding disability, the individuals who presented the highest prevalence of hypertension were more dependent. In stepwise multivariable regression analysis, the presence of obesity, diabetes, as well as disability was independently associated with hypertension (Table 3).

\section{Discussion}

\section{Prevalence of hypertension}

This study provides important new evidence on the prevalence of hypertension in a representative sample of an elderly population in a geographically well defined Mediterranean area of the Tunisia center. Moreover, it has already established socio-demographic variables and drug consumption. A peculiar aspect of our population is the low level of education ( $89 \%$ for illiterates plus subjects with kuttabs education).

We observed that more than $50 \%$ of elderly in Monastir city suffer from hypertension. Since the use a BP value of $140 / 90 \mathrm{mmHg}$ as cut-off, the prevalence of hypertension has increased. These percentage values have also been found in studies carried out in North African countries such as Morocco [13], and other Arab countries such as Egypt [14]. Laouani reported a prevalence rate of $69.3 \%$ [15] but in 2000, Kammoun et al. reported in a representative sample of the Tunisian elderly population the prevalence of $32 \%$ [16]. The increasing prevalence of hypertension among the elderly population of Monastir city may be attributed to change in lifestyle in the past decade. However, the prevalence of hypertension is still considerably lower than in other industrialised countries such as France (79.8\%), England (62\%), Greece (65.4\%), Spain (62\%), Italy (76.3\%) and United States (84\%) [17-22].

This study showed clear gender differences in the prevalence of hypertension, with women being more likely to be hypertensive than men. The gender differences in the prevalence of hypertension have been reported in many studies [21-23]. The present study found that

Table 3 Correlates of prevalent hypertension among the study subjects (results of multiple logistic regression analysis)

\begin{tabular}{cllc}
\hline Variable & $\boldsymbol{\beta}$-Coefficient & Odds ratio & $\boldsymbol{p}$ value \\
\hline Diabetes & $0.81(0.22)^{c}$ & $2.06 ; 1.45-3.5^{\mathrm{d}}$ & $\mathrm{P}<0.001$ \\
BMl $^{\mathrm{b}}$ & $0.65(0.20)$ & $2.01 ; 1.48-2.47$ & $\mathrm{P}<0.01$ \\
Dependency & $0.63(0.15)$ & $1.6 ; 0.9-2.7$ & $\mathrm{P}<0.001$ \\
\hline
\end{tabular}

\footnotetext{
${ }^{a}$ Age, sex, marital status, region, educational level, physical activity, depression were not statistically significant. ${ }^{b}$ BMI Body Mass Index. ${ }^{c}$ Figures in parentheses are standard errors.

${ }^{d}$ Figures in italics are $95 \%$ confidence intervals.
} 
hypertension prevalence declined after 80 years, the difference might partly be due to the shorter survival of people with $\mathrm{AH}$ and a low incident in the older age group. As demonstrated in this study, isolated systolic hypertension is the most common form of hypertension found in elderly [24]. The predominance of systolic hypertension may reflect the consequences of a tendency for clinicians to treat it less aggressively than diastolic hypertension.

\section{Awareness, treatment and control of hypertension}

Only $19 \%$ of the respondents were newly diagnosed with hypertension. Although these proportions are quite similar to those reported from other developing countries [25]. Population studies have shown different rate of hypertension awareness by hypertensive individuals. In European countries, these levels range from $52.7 \%$ in Germany to $70 \%$ in Sweden. In Canada and USA the awareness rate is $83 \%$ and $87.3 \%$ respectively [26,27]. In these studies, the degree of awareness of hypertension was high (81\%) than those reported by the India study [28]. Wyatt et al. reported that awareness significantly increased with age, female sex, presence of major co-morbidity and receiving preventive care [29], a combination of these factors contributes to the high level of awareness in our study.

Among treated hypertensive individuals in this study, about $30 \%$ had blood pressure controlled. These data are also similar to those reported by Liau et al. (34.3\%) [23], but lower than those reported by Cipullo et al. (52.4\%). In Europe the blood pressure controls rate range from $22.9 \%$ in Spain to $37.7 \%$ in England [26]. The favourable results in our study may be due to adequate public information about hypertension and availability of free government-supplied anti hypertensive drugs with relatively high access to health care and insurance coverage.

\section{Correlates of hypertension}

Regarding the educational level, there are an inverse but not significantly association between schooling and $\mathrm{AH}$, the small number of educated population may influence this result. Although, this finding was consistent with previous reports [30,31]. Cipullo et al. reported that the risk of hypertension was 2.8-times higher for those with lower schooling [26]. There is an intricate relationship between physical health and psychological status. Depression is known to have diverse effects on body functions. A French study of the elderly in the community revealed that hypertension was associated with anxiety but not depression [32]. Our study showed the lack of association between depression symptoms and incident hypertension.
The benefits of physical activity in the prevention and treatment of high blood pressure have been very well described [33]. In the present study, physical activity was not at a reduced risk for hypertension, but selfreported bias and interviewer bias can result in no differential misclassification.

The higher, but not significant, prevalence of hypertension in non smokers should be interpreted with caution since it is possible that part of the existing difference may be due to the high percentage of current smokers for male compared to female. No association between $\mathrm{AH}$ and marital status, these results are in accordance to what has been reported in other study [28]. In Martinique and China populations, the urban population exhibit a risk profile of hypertension [34,35], but not urban/rural differences were observed in our study, it is important to note that in our study in Monastir City, only $14 \%$ are from rural sites, the small number may influence statistics. The higher prevalence rates in hypertension among the illiterate and in individuals living in urban area are often being attributed to differences in life style, modernization, a shift from an agricultural to non agricultural economy, physical activity and occupation. Socioeconomic difference play, also, an important role in health conditions influencing different factors such as access to the health system, degree of information and understanding of medical conditions $[36,37]$.

Similar to several population-based studies [26,38,39], it was observed that there is an important association between BMI and $\mathrm{AH}$, as well as waist circumference. Overweight and obesity are actual risk factors for hypertension. The positive correlation between waist circumference and AH identifies a simple, low cost and easyto-apply measure as an important marker for $\mathrm{AH}$.

The strong association between diabetes mellitus and hypertension has been reported by numerous studies $[28,40]$. It is widely appreciated that hypertension increase the risk of activities of daily living and instrumental activities of daily living decline and have an important impact on the dependency categories [41], our data support this observation.

\section{Limitations of the study}

Some limitations of this study should be mentioned: first the use of a single visit to ascertain hypertension status can result in an over-estimation of its prevalence. Other potential sources of bias include the self-reported hypertensive treatment by the participants. Treatment status was assessed by the question of whether or not the person was currently using antihypertensive drugs (within the last two weeks). No information on type and dosage of antihypertensive medication being used or medication compliance was collected from participants, nor were 
they asked about AH control measures other than pharmacotherapy. Therefore, "treatment" was restricted to the use of medication, without consideration of other, non pharmaceutical strategies such as dietary sodium restriction.

In this study, we did not assess the lipid profile and blood glucose measurement, a fact that did not allow us to evaluate the association between the metabolic changes and high BP.

We used BMI as a simple method to categorize people as "healthy weight," "overweight," or "obese". BMI formula may overestimates fatness in elderly because of loss of height resulting from vertebral compression (a problem commonly associated with aging). Knee-heel length and weight/knee height as alternative measurements in the elderly were not measured.

On the other hand, we described the prevalence of hypertension among the elderly in Monastir city, in order to provide estimates of the problem, this adding information about a group that is under researched. The use of a door-to door survey, the large sample size, adequate representation of women and the very old and a health professional for blood pressure measurement are strengths of our study.

\section{Conclusions}

Our findings provide important information on the prevalence, awareness and control of hypertension. More than half of our study population was classified as hypertensive. The magnitude of arterial hypertension in elderly had important implications for both health care and health promotion and poses a major economic challenge. The public health community must be alerted to the emergence of arterial hypertension as an important health problem. Despite high prevalence in Monastir city, our study suggest that educational efforts, individual level strategies combined with population level efforts directed at increasing the levels of awareness and treatment and reducing the average blood pressure of the population. After the estimation of the prevalence of hypertension, the formulation of effective treatment strategies is very important. Consequently, it is important that health planners, clinicians and public health practitioners formulate country-specific guidelines according to health care system in developing countries and her economic realities.

\section{Acknowledgements and Funding}

The authors thank all subjects who participated in the study. We express our thanks to the Association of Elderly Protection in Monastir, especially her President Pr Noureddine Bouzouaia and Pr Hala Sweed, Geriatric and Gerontology Unit in University of Ain Shams Egypt for her invaluable help and suggestion. We highly acknowledge the contribution by the participating doctors: Najeh Benamor. Nadia Hammami and Sondos Dimassi. The study was supported by grants from World Health Organisation (EMRO), additionally; the study has been supported by the United Nations Population Fund (UNFPA) Tunisian section.

\section{Author details}

${ }^{1}$ Laboratory of Nutrition and Vascular Health, Faculty of Medicine, University of Monastir, Tunisia. ${ }^{2}$ Internal Medicine Department, University Hospital "F. Bourguiba" Monastir, Tunisia. ${ }^{3}$ National Institute of Public Health Tunis, Tunisia. "Nephrology Department, University Hospital "F. Bourguiba" Monastir, Tunisia. ${ }^{5}$ Pneumology Department, Geriatric unit, University Hospital H Chaker Sfax, Tunisia. ${ }^{6}$ Cardiology Department, University Hospital "F. Bourguiba" Monastir, Tunisia.

\section{Authors' contributions}

SoH initiated, directed and designed the research, contributed to data collection, interpretation of results and drafted the manuscript. SM participated in the recruitment of study subjects and collection epidemiological data and contributed to the preparation of the final manuscript. SH contributed to study design, to assembly of data and interpretation of results performed the statistical analysis. NK participated in the recruitment of study subjects and collection epidemiological data. MAF contributed to assembly of data and commented on the manuscript. SK contributed to study design interpretation of results and commented on the manuscript. $\mathrm{MH}$ and FB supervised the study including interpretation of results and preparation of the manuscript. All authors read and approved the final manuscript.

\section{Competing interests}

The authors declare that they have no competing interests.

Received: 21 April 2011 Accepted: 1 November 2011

Published: 1 November 2011

\section{References}

1. Lee DS, Massaro JM, Wang TJ, Kannel WB, Benjamin EJ, Kenchaiah S, Levy D, D'Agostino RB Sr, Vasan RS: Antecedent blood pressure, body mass index and the risk of incident heart failure in later life. Hypertension 2007, 50:869-876.

2. World Health Organization: Global Health risks; Mortality and Burden of disease attributable to Selected Major Risks. Geneva: World Health Organization Press; 2009

3. Hajjar I, Kotchen TA: Trends in prevalence, awareness, treatment and control of hypertension in the USA, 1988-2000. J Am Med Assoc 2003, 290:199-206.

4. Hanon O: Hypertension in the elderly: particularities and precautions. Press Med 2009, 38:614-620.

5. Hanon O, Seux LL, Rigaud AS: Hypertension in the elderly. EMC Medicine 2004, 1:381-387.

6. Tunisian National Institute of Statistics: Information about population census.[http://www.ins.nat.tn].

7. Chobanian AV, Bakris GL, Black HR, Cushman WC, Green LA, Izzo JL Jr, Jones DW, Materson BJ, Oparil S, Wright JT Jr, Roccella EJ, National Heart, Lung, and Blood Institute Joint National Committee on Prevention, Detection Evaluation, and Treatment of High Blood Pressure; National High Blood Pressure Education Program Coordinating Committee: The Seventh Report of the Joint National Committee on Prevention, Detection, Evaluation, and Treatment of High Blood Pressure: the JNC 7 report. JAMA 2003, 289:2560-2572.

8. WHO World Health Organization: Obesity: preventing and managing the global epidemic. Geneva, WHO; 1997

9. Grundy SM, Brewer HB Jr, Cleeman Jl, Smith SC Jr, Lenfant C, American Heart Association; National Heart and Blood Institute: Definition of metabolic syndrome: Report of the National Heart, Lung, and Blood Institute/American Heart Association conference on scientific issues related to definition. Circulation 2004, 109:433-438.

10. American Diabetes Association: Diagnosis and classification of diabetes mellitus. Diabetes Care 2007, 30(Suppl 1):S42-S47.

11. Katz S, Ford AB, Moskowitz RW, Jackson BA, Jaffe MW: Studies of illness in the aged The index of ADL: a standardized measure of biological and psychosocial function. JAMA 1963, 185:94-99.

12. Clement JP, Nassif RF, Leger JM, Marchan F: Development and contribution to the validation of a brief French version of the Yesavage Geriatric Depression Scale. Encephale 1997, 23:91-99. 
13. Tazi MA, Khalil SA, Chaouki N, Cherquaoui S, Lahmouz F, Srairi JE, Mahjour J: Prevalence of the main cardiovascular risk factors in Morocco/results of a national survey, 2000. J Hypertens 2003, 21:897-903.

14. Ibrahim MM, Rizk H, Appel LJ, el Aroussy W, Helmy S, Sharaf Y, Ashour Z, Kandil H, Roccella E, Whelton PK: Hypertension Prevalence, Awareness, treatment, and control in Egypt. Results from the Egyptian Natonal Hypertension Project (NPH). NPH Investigative Team. Hypertension 1995, 26:886-890.

15. Laouani K C, Hamouda H, Ben Naceur MH, Ghannem H, Toumi S, Ajmi F: Hight blood pressure for people aged more than 60 years in the district of Sousse. Tunis med 2004, 82:1001-1005.

16. Kammoun M, Hajem S, Gueddana N, Achour N, Slimane H: Diabetes, hypertension, obesity in elderly study about 981 aged 65 years and over. Rev Geriatrie 2006, 31:477-486.

17. Wagner A, Arveiler D, Ruidavets JB, Cottel D, Bongard V: Summary statements of hypertension in France in 2007. the Mona Lisa study BEH 2008, 49:483-486.

18. Primatesta P, Poulter NR: Hypertension management and control among English adults aged 65 years and older in 2000 and 2001. J Hypertens 2004, 22:1093-1098.

19. Efstratopoulos AD, Voyaki SM, Baltas AA, Vratsistas FA, Kirlas DE, Kontoyannis JT, Sakellariou JG, Triantaphyllou GB, Alokrios GA, Lianas DN, Vasilakis EA, Fotiadis KN, Kastritsea EE: Prevalence, Awareness, treatment and control of hypertension in Hellas, Greece: the Hypertension Study in General Practice in Hellas (HYPERTENSHELL) national study. Am J Hypertens 2006, 19:53-60.

20. Martin-Baranera M, Sanchez Ferrin P, Armario P: Prevalence of hypertension in elderly long-term care residents in Spain. The geriatric HTA study. Medicina clinica 2006, 127:681-687.

21. Cacciatore F, Gallo C, Ferrara N, Abete P, Paolisso G, Canonico S, Signoriello G, Terracciano C, Napoli C, Varricchio M, Rengo F: Morbidity patterns in aged population in southern Italy. A survey sampling. Arch Gerontol Geriat 1998, 26:201-213.

22. Hajjar I, Kotchen TA: Trends in prevalence, awareness, treatment, and control of hypertension in the United States, 1988-2000. JAMA 2003, 290:199-206.

23. Liau CS, Tseng YZ, Lee TK: Prevalence of cardiovascular diseases in elderly Chinese people in Taiwan. Int J cardiol 1998, 67:177-81.

24. Paciaroni E, Fraticelli A, Antonicelli R: Arterial hypertension in the elderly: A review. Arch Gerontol Geriatr 1996, 23:257-64.

25. Shapo L, Pomerleau J, McKee M: Epidemiology of hypertension and associated cardiovascular risk factors in a country in transition: a population based survey in Tirana City, Albania. J Epidemiol Community Health 2003, 57:734-39.

26. Cipullo J P, Martin JF, Ciorlia LA, Godoy MR, Cação JC, Loureiro AA, Cesarino CB, Carvalho AC, Cordeiro JA, Burdmann Ede A: Hypertension prevalence and risk factors in a Brazilian Urbain Population. Arq Bras Cardiol 2010, 94:519-26.

27. Wilkins K, Campbell NRC, Joffres MR, McAlister FA, Nichol M, Quach S, Johansen HL, Tremblay MS: Blood Pressure in Canadian adults. Health Rep 2010, 21:37-46.

28. Hypertension Study Group: Prevalence, awareness, treatment and control of hypertension among the elderly in Bangladesh and India: a multicentre study. Bull World Health Organ 2001, 79:490-500.

29. Wyatt ShB, Akylbekova AL, Wofford MR, Coady SA, Walker ER, Andrew ME, Keahey WJ, Taylor HA, Jones DW: Prevalence, Awareness, Treatment, and Control of Hypertension in the Jackson Heart study. Hypertension 2008, 51:650-556.

30. Jardim V, Gondim M, Monego ET, Moreira HG, Vitorino PV, Souza WK, Scala LC: High blood pressure and some risk factors in a Brazilian capital. Arq Bras cardiol 2007, 88:398-403.

31. Ong KL, Cheung BMY, Man YB, Lau CP, Lam KSL: Prevalence, awareness, treatment, and control of hypertension among United States adults 1999-2004. Hypertension 2007, 49:69-75.

32. Paterniti S, Alperovitch A, Ducimetiere P, Dealberto MJ, Lepine JP, Bisserbe JC: Anxiety but not depression is associated with elevated blood pressure in a community group of French elderly. Psychosom Med 1999, 61:77-83.

33. Whelton SP, Chin A, Xin X, He J: Effects of aerobic exercise on blood pressure: a meta-analysis of randomized, controlled trials. Ann Intern Med 2002, 136:493-503.
34. Merle S, Pierre Louis K, Rosine J, Cardoso T, Inamo J, Deloumeaux : Arterialhypertension prevalence in the general population of Martinique. Rev Epidemiol Santé Publique 2009, 57:17-23.

35. Wang Z, WU Y, Zhao L, Li Y, Yang J, Zhou B: Trends in prevalence, awareness, treatment and control of hypertension in the Middle aged population of China, 1992-1998. Hypertens Res 2004, 27:703-709.

36. Damasceno A, Azevedo A, Siva matos C, Prista A, Diogo D, Lunet N: Hypertension Prevalence, Awareness, treatment, and control in Mozambique (urban/rural gap during epidemiological Transition). Hypertension 2009, 54:77-83.

37. Pereira $\mathrm{M}$, Lunet $\mathrm{N}$, Azevedo A, Barros $\mathrm{H}$ : Differences in prevalence awareness, treatment and control of hypertension between developing and developed countries. J hypertens 2009, 27:963-975.

38. Oda E, Kawai R: Body mass index is more strongly associated with hypertension than waist circumference in apparently healthy Japanese men and women. Acta Diabetol 2010, 47:309-913.

39. Stamler J: Epidemiological Findings on Body Mass and Blood Pressure in Adults. Ann Epidemiology 1991, 1:347-362.

40. Epstein M, Sowers JR: Diabetes mellitus and hypertension. Hypertension 1992, 19:403-418.

41. Alves LC, Quinet Leimann BC, López Vasconcelos ME, Sá Carvalho M, Godoi Vasconcelos AG, Oliveira da Fonseca TC, Lebrão ML, Laurenti R: The effect of chronic diseases on functional status of the elderly living in the city of São Paulo. Brazil Cad Saude Publica 2007, 23:1924-1930.

\section{Pre-publication history}

The pre-publication history for this paper can be accessed here: http://www.biomedcentral.com/1471-2261/11/65/prepub

doi:10.1186/1471-2261-11-65

Cite this article as: Hammami et al:: Awareness, treatment and control of hypertension among the elderly living in their home in Tunisia. BMC Cardiovascular Disorders 2011 11:65.

\section{Submit your next manuscript to BioMed Central and take full advantage of:}

- Convenient online submission

- Thorough peer review

- No space constraints or color figure charges

- Immediate publication on acceptance

- Inclusion in PubMed, CAS, Scopus and Google Scholar

- Research which is freely available for redistribution

Submit your manuscript at www.biomedcentral.com/submit
C Biomed Central 